\title{
EFFECT OF DEPRESSIVE SYMPTOMS AND HIV EXPOSURE ON THE QUALITY OF LIFE OF HIV-SEROPOSITIVE AND SERONEGATIVE PREGNANT WOMEN
}

\author{
Ester Zoche ${ }^{1,2}$, Vera Lúcia Bosa ${ }^{2,3,4}$, Eunice Beatriz Martin Chaves², \\ Edison Capp ${ }^{1}$, Helena von Eye Corleta ${ }^{1}$
}

Clin Biomed Res. 2019;39(2):116-121

1 Programa de Pós-graduação em Ginecologia e Obstetrícia, Universidade Federal do Rio Grande do Sul (UFRGS) Porto Alegre, RS, Brasil.

2 Serviço de Nutrição e Dietética, Hospital de Clínicas de Porto Alegre (HCPA) Porto Alegre, RS, Brasil.

3 Centro de Estudos em Alimentação e Nutrição (CESAN), Hospital de Clínicas de Porto Alegre (HCPA). Porto Alegre, RS, Brasil.

4 Programa de Pós-graduação em Alimentação, Nutrição e Saúde, Universidade Federal do Rio Grande do Sul (UFRGS). Porto Alegre, RS, Brasil.

Corresponding author:

Ester Zoche

esterzoche@gmail.com

Hospital de Clínicas de Porto Alegre (HCPA)

Rua Ramiro Barcelos, 2350

90035-903, Porto Alegre, RS, Brasil.

\begin{abstract}
Introduction: Depression among human immunodeficiency virus (HIV)-seropositive individuals has been associated with reduced quality of life. The aim of the study was to evaluate the effect of depressive symptoms and HIV exposure on mean quality of life scores in HIV-seropositive and HIV-seronegative postpartum women.
\end{abstract}

Methods: A cross-sectional study was conducted with two groups: $80 \mathrm{HIV}$-seropositive and 80 HIV-seronegative postpartum women. The Edinburgh Postnatal Depression Scale and the World Health Organization Quality of Life short-version scale were used to assess presence of depressive symptoms and quality of life scores. Two-way analysis of variance was used to compare the effects of depressive symptoms, HIV exposure and interaction between depressive symptoms and HIV exposure on mean quality of life scores, with $p<0.05$ considered statistically significant.

Results: Depressive symptoms were present in 35\% (28) of HIV-seropositive and $17.5 \%$ (14) of HIV-seronegative participants $(p=0.02)$. The interaction between depressive symptoms and HIV exposure was not significant for any quality of life domain. The main effect of HIV exposure was also not significant. Depressive symptoms had a negative influence on quality of life scores in all domains (physical health, psychological health, social relationships and environment) $(p<0.001)$.

Conclusions: The quality of life of pregnant women is negatively influenced by the presence of depressive symptoms.

Keywords: Pregnancy; quality of life; depression and HIV

Quality of life (QoL) can be defined as individuals' perception of their position in life and their values, goals, expectations, standards and concerns ${ }^{1}$. Many factors can affect the QoL of pregnant women, particularly changes in sleep, worries, anxiety, depression and excessive weight gain ${ }^{2}$. Kapetanovic et al. ${ }^{3}$ report that the psychiatric health and QoL of human immunodeficiency virus (HIV)-seropositive women may be affected by depression and other mental health conditions ${ }^{3}$. A high prevalence of depressive symptoms and other mental health-related vulnerabilities associated with adverse pregnancy outcomes and decreased QoL have been described in this population. Depression among HIV-seropositive individuals has been associated with lower scores in the psychological, social and environmental domains of $\mathrm{QoL}^{4}$. A study conducted on HIV-seropositive pregnant women in an urban setting in Brazil found lower scores for domains related to secrecy and financial matters among this group ${ }^{5}$. A systematic review of African studies found substantial rates of depressive symptoms and emotional distress among HIV-seropositive pregnant women. Rates of depression are also high among HIV-seropositive pregnant women in developed countries and, regardless of the country, HIV-seropositive pregnant women have lower levels of education ${ }^{3}$. In a cross-sectional study of 633 HIV-seropositive African women, $48.7 \%$ had depressed mood, which was associated with unplanned pregnancies, HIV-infected children, domestic violence, non-use of condoms in recent years, and poor adherence to antiretroviral medication ${ }^{6}$. Depression 
is commonly associated with negative beliefs about the disease and feelings of hopelessness, which undermine individuals' motivation to care for their health, reducing confidence in their ability to cope with the demands of treatment ${ }^{7}$.

Potential risk factors for prenatal and postnatal depression in women are the following: age under 18 years, race, low level of education, living in deprived areas, low socioeconomic status, sociocultural beliefs, unplanned pregnancy, health problems during pregnancy, domestic violence and lack of family support ${ }^{8}$. A study of 179 pregnant women in Italy found that postpartum depression was associated with lack of social support and negative outcomes in pregnancy. The authors concluded that social support during pregnancy plays an important role in preventing effects of postpartum depression on newborn outcomes ${ }^{9}$.

A recent review describing QoL during uncomplicated pregnancy showed that symptoms of depression, anxiety, and stress were factors that had a strong negative impact on the QoL of pregnant women. They reinforce that, in some countries, QoL of pregnant woman has been little studied and no specific mechanism has been found to explain the association ${ }^{10}$.

In view of the possible relationship between depressive symptoms and poorer QoL scores, the present study aimed to evaluate, in the immediate puerperium, the effect of depressive symptoms and HIV exposure on mean QoL scores of HIV-seropositive and HIV-seronegative women.

\section{MATERIAL AND METHODS}

This cross-sectional study was conducted at the obstetric unit of a tertiary hospital in Porto Alegre, southern Brazil, with two groups of puerperal women aged 18 years or older, either HIV-seropositive or HIV-seronegative, between July 2015 and July 2016. The sample was selected using medical records of hospitalized HIV-seropositive postpartum women. The selection of HIV-negative postpartum women followed the HIV-seropositive bed rule. Data were collected in the immediate puerperium (up to 48 hours postpartum), using a questionnaire on age, skin color, education, marital status, type of delivery, tobacco, alcohol and drug use, parity, time since HIV diagnosis, and time since beginning antiretroviral therapy. Socioeconomic status was categorized as class A-B, C or D-E according to the Brazilian Economic Classification Criteria scoring system (2015 update), where class A represents the highest status and class $E$ represents the lowest status ${ }^{11}$.

The presence of maternal depressive symptoms was determined according to the Edinburgh Postnatal Depression Scale (EPDS), translated and validated for Brazilian Portuguese. This self-administered questionnaire consists of ten items scored on a 4-point scale. The cut-off score used for depressive symptoms was $11-12$, and participants with scores $\geq 12$ were considered positive for depressive symptoms ${ }^{12}$. Although the scale determines an increased risk of developing depression, it does not consist of a diagnosis of depression. QoL was assessed using the World Health Organization Quality of Life short-version (WHOQOL-BREF) instrument, translated and adapted for the Brazilian context. This instrument consists of 26 questions and is divided into four domains, namely physical health, psychological health, social relationships and environment ${ }^{13}$. There is no QoL cut-off score; thus, scores closer to 100 indicate better QoL, while those closer to zero indicate poorer QoL.

Statistical analysis was performed in SPSS, version 18.0. For comparing groups exposed and not exposed to HIV, Student's t-test was used for continuous variables with normal distribution, and results were expressed as mean and standard deviation. Pearson's chi-square test with Yate's correction for continuity was used for categorical variables, which were described as percentage and relative frequency. Two-way analysis of variance (ANOVA) was used to compare the effects of depressive symptoms, HIV exposure and the interaction between depressive symptoms and HIV exposure on mean QoL. P-values lower than 0.05 were considered statistically significant.

The research project was approved by the Research Ethics Committee of the relevant institution (case no. 15/0249) and followed all regulations for research involving human subjects (resolution no. 466/2012). All participants signed an informed consent form that ensured the confidentiality of their identity and the data obtained.

\section{RESULTS}

A total of 160 postpartum women participated in the study; 80 were HIV-seronegative and 80 were HIV-seropositive. Table 1 shows the characteristics of the sample. The HIV-seropositive group was significantly older $(p<0.001)$, had a lower educational level $(p<0.001)$, had a higher proportion of individuals belonging to a lower socioeconomic status $(p=0.014)$, had a higher proportion of unemployed participants $(p=0.011)$, had a higher proportion of non-whites $(p=0.004)$, had a higher proportion of participants without a partner $(p<0.001)$ and had a higher proportion of smokers $(p=0.03)$. Depressive symptoms were present during gestation in $35 \%$ of the HIV-seropositive group (28 patients) and in $17.5 \%$ of the HIV-seronegative group (14 patients), showing a significant difference $(p=0.02)$. There was no difference between the groups for alcohol and drug use during pregnancy.

Regarding HIV diagnosis, $66.2 \%(n=53)$ of the HIV-seropositive group were diagnosed during pregnancy, although length of time since diagnosis did not significantly affect depressive symptom scores $(p=0.451)$. Of the infected women, $97.5 \%$ were on antiretroviral therapy during pregnancy; 
$47.43 \%(n=37)$ began prior to pregnancy and $52.56 \%(n=41)$ began during pregnancy. Viral load was undetectable in $78.8 \%(n=63)$ of seropositive patients after 34 weeks. The median time since diagnosis was two [0-6] years.
Table 2 reports presence of depressive symptoms, HIV exposure and the interaction between these two factors on mean QoL scores. The interaction between depressive symptoms and HIV exposure had no significant effect on QoL domains. HIV exposure also

Table 1: Social characteristics, presence of depressive symptoms in HIV-seronegative (HIV-) and HIV-seropositive (HIV+) pregnant women.

\begin{tabular}{|c|c|c|c|}
\hline & HIV- & HIV+ & $p^{* * *}$ \\
\hline Age (years)* & $25.6( \pm 4.9)$ & $28.8( \pm 5.9)$ & $<0.001$ \\
\hline Education (years) ${ }^{*}$ & $10.0( \pm 2.3)$ & $8.6( \pm 2.2)$ & $<0.001$ \\
\hline Skin color ${ }^{* *}$ & & & 0.004 \\
\hline White & $77.5 \%(62)$ & $55 \%(44)$ & \\
\hline Non-white & $22.5 \%(18)$ & $45 \%(36)$ & \\
\hline Socioeconomic status ${ }^{* *}$ & & & 0.014 \\
\hline Class A-B & $22.5 \%(18)$ & $6.3 \%(5)$ & \\
\hline Class C & $63.7 \%(51)$ & $76.2 \%(61)$ & \\
\hline Class D-E & $13.8 \%(11)$ & $17.5 \%(14)$ & \\
\hline Marital status ${ }^{* *}$ & & & $<0.001$ \\
\hline With partner & $91.3 \%(73)$ & $63.8 \%(51)$ & \\
\hline Without partner & $8.7 \%(7)$ & $36.2 \%(29)$ & \\
\hline Employed** & $62.5 \%(50)$ & $41.5 \%(33)$ & 0.011 \\
\hline Smoking ${ }^{* *}$ & $17.5 \%(14)$ & $33.7 \%(27)$ & 0.030 \\
\hline Alcohol consumption** & $20 \%(16)$ & $17.5 \%(14)$ & 0.839 \\
\hline Drug consumption** & $2.5 \%(2)$ & $7.5 \%(6)$ & 0.277 \\
\hline Presence of depressive symptoms ${ }^{* *}$ & $17.5 \%(14)$ & $35.0 \%(28)$ & 0.020 \\
\hline
\end{tabular}

*Student's t-test: mean (standard deviation); ${ }^{* *}$ Chi-square test: percentage (absolute frequency); ${ }^{* * *} p<0,05$ (significant diference between the groups); HIV = human immunodeficiency virus.

Table 2: Comparison of quality of life scores by physical health, psychological health, environment and social relationships domains with presence of depressive symptoms and HIV exposure in the gestational period of HIV-seropositive and HIV-seronegative women.

\begin{tabular}{|c|c|c|c|c|c|c|c|}
\hline \multirow[b]{2}{*}{ Domains } & \multirow{2}{*}{$\begin{array}{l}\text { Presence of } \\
\text { depressive } \\
\text { symptoms }\end{array}$} & \multicolumn{2}{|c|}{ HIV exposure } & \multirow[b]{2}{*}{ Total } & \multirow{2}{*}{$\begin{array}{c}p \\
\text { Depressive } \\
\text { symptoms }\end{array}$} & \multirow{2}{*}{$\begin{array}{c}p \text { HIV } \\
\text { exposure }\end{array}$} & \multirow[b]{2}{*}{$\stackrel{p}{p}$} \\
\hline & & $\frac{\text { HIV+ }}{\text { Mean }[95 \% \mathrm{Cl}]}$ & $\begin{array}{c}\text { HIV- } \\
\text { Mean }[95 \% \mathrm{Cl}]\end{array}$ & & & & \\
\hline \multirow{3}{*}{$\begin{array}{l}\text { Physical } \\
\text { health }\end{array}$} & No & $70.7[66.8 ; 74.6]$ & $74.1[70.6 ; 77.5]$ & $72.4[69.8 ; 75.0]$ & $<0.001$ & 0.673 & 0.395 \\
\hline & Yes & 57.3 [52.0;62.6] & 56.1 [48.6;63.6] & 56.7 [52.1;61.3] & & & \\
\hline & Total & $64.0[60.7 ; 67.3]$ & $65.1[61.0 ; 69.2]$ & & & & \\
\hline \multirow{3}{*}{$\begin{array}{l}\text { Psychological } \\
\text { health }\end{array}$} & No & $75.0[72.2 ; 77.8]$ & 77.8 [75.4;80.3] & 76.4 [74.6;78.3] & $<0.001$ & 0.693 & 0.273 \\
\hline & Yes & $61.5[57.7 ; 65.2]$ & $60.1[54.8 ; 65.4]$ & $60.8[57.5 ; 64.1]$ & & & \\
\hline & Total & $68.2[65.9 ; 70.6]$ & $69.0[66.0 ; 71.9]$ & & & & \\
\hline \multirow[t]{3}{*}{ Environment } & No & $63.6[59.5 ; 67.6]$ & $62.8[59.2 ; 66.4]$ & $63.2[60.5 ; 65.9]$ & $<0.001$ & 0.056 & 0.100 \\
\hline & Yes & $55.2[49.7 ; 60.8]$ & $45.3[37.5 ; 53.1]$ & $50.3[45.5 ; 55.0]$ & & & \\
\hline & Total & $59.4[56.0 ; 62.8]$ & $54.1[49.8 ; 58.4]$ & & & & \\
\hline \multirow{3}{*}{$\begin{array}{l}\text { Social } \\
\text { relationships }\end{array}$} & No & $81.4[76.8 ; 86.0]$ & $82.3[78.2 ; 86.4]$ & $81.9[78.8 ; 85.0]$ & $<0.001$ & 0.610 & 0.426 \\
\hline & Yes & $66.7[60.4 ; 73.0]$ & $62.5[53.6 ; 71.4]$ & $64.6[59.1 ; 70.0]$ & & & \\
\hline & Total & $74.0[70.1 ; 78.0]$ & $72.4[67.5 ; 77.3]$ & & & & \\
\hline \multirow[t]{3}{*}{ Total score } & No & $72.7[69.7 ; 75.6]$ & 74.3 [71.6;76.9] & 73.5 [71.5;75.4] & $<0.001$ & 0.531 & 0.158 \\
\hline & Yes & $60.2[56.1 ; 64.2]$ & $56.0[50.3 ; 61.7]$ & $58.1[54.6 ; 61.6]$ & & & \\
\hline & Total & $66.4[63.9 ; 68.9]$ & $65.1[62.0 ; 68.3]$ & & & & \\
\hline
\end{tabular}

Two-way analysis of variance (ANOVA): mean [95\% confidence interval, Cl]; $\boldsymbol{p}$ interaction $=p$-value of the interaction between presence of depressive symptoms and HIV exposure; HIV = human immunodeficiency virus. 
had no significant effect on mean QoL. Conversely, depressive symptoms influenced mean QoL in all domains (physical health, psychological health, social relationships and environment) and in total score $(p<0.001)$, showing that mean QoL scores were lower in pregnant women with positive depressive symptom scores $(\geq 12)$. Although there is no cut-off point for stratifying QoL scores, significantly lower values were observed in postpartum women with depressive symptoms. The differences in mean QoL domain scores between the groups ranged from 12.9 (environment domain) to 17.3 (social relationship domain).

\section{DISCUSSION}

The present study evaluated the effects of depressive symptoms and HIV exposure on QoL scores of HIV-seropositive and HIV-seronegative postpartum women in southern Brazil. There was a negative relationship between QoL scores and depressive symptoms, regardless of HIV exposure.

The mean age and parity of HIV-seropositive postpartum women were significantly higher than those of HIV-seronegative women. Koenig et al. ${ }^{14}$ also reported an association of HIV infection with higher pregnancy rates. A Brazilian study of HIV-infected pregnant women showed that almost half of them $(48.9 \%)$ had had at least two previous pregnancies ${ }^{15}$. A higher parity in the HIV-seropositive group could also be explained by a higher mean age. The mean level of education in the HIV-seropositive group was lower (8.6 \pm 5.9 years studying) than in the HIV-seronegative group (10 \pm 2.3 years), and more HIV-seropositive women had lower socioeconomic status. A recent National Epidemiological Bulletin on HIV found that the majority of the HIV-positive population in Brazil has been infected for five and eight years ${ }^{16}$. Yaya et al. ${ }^{17}$ found that individuals with a low educational level have less understanding about HIV and its forms of transmission than those with a higher educational level; thus, there is an increased risk of transmission among the disadvantaged. A study conducted in Africa showed that poorer populations are at higher risk of HIV infection, with women having a higher risk, regardless of socioeconomic status ${ }^{18}$. Lack of information and low educational levels can influence self-care and risk behaviors, thus increasing the risk of HIV infection.

The literature reports increased use of tobacco, alcohol and drugs among HIV-seropositive pregnant women $^{19,20}$. A 2017 study on pregnant African women found a smoking rate of $32.7 \%{ }^{21}$, similar to that found in our study (33.8\%). In the present study, the similar use of drugs and alcohol in HIV-seronegative and HIV-seropositive women may be due to the embarrassment of responding positively in the immediate postpartum period. A total of $36.2 \%$ of the HIV-seropositive group reported not living with a partner, which is consistent with the study of Lima et al. ${ }^{15}$, which reported that $50 \%$ of HIV-infected young pregnant women did not have a stable sexual partner. A cross-sectional study conducted in Brazil with 2,145 women, 713 of whom were infected with HIV, also found that HIV-positive women were less likely to have a stable partner ${ }^{22}$.

Depressive symptoms were significantly more frequent during pregnancy in the HIV-seropositive group $(35 \%)$ than in the HIV-seronegative group $(17 \%)$. The literature varies widely regarding diagnosis and/or symptoms of depression in this population. Calvetti et al. ${ }^{7}$ found that $24.8 \%$ of young adults with HIV had symptoms of anxiety, sadness, fear, low self-esteem and guilt. In a cross-sectional study of 633 HIV-seropositive African women, $48.7 \%$ of the sample had depressed mood ${ }^{6}$. Donald et al. ${ }^{21}$ reported moderate or high depression in $35.88 \%$ of postpartum women infected with HIV, similar to the rate found in our study. Such studies have shown concordance in their results, in which HIV-seropositive pregnant women have higher rates of depressive symptoms. These findings seem to show that HIV affects psychological aspects and increases scale scores indicating depression.

Regarding the interaction between depressive symptoms and HIV exposure on QoL domains, significant associations have been found between mean QoL scores and depressive symptoms, regardless of HIV exposure. Consistent with our findings, Sut et al. ${ }^{23}$ reinforced that psychiatric disorders affect the physical and psychological domains of QoL during pregnancy. Shrestha et al. ${ }^{24}$ demonstrated that a feeling of social support improves the perception of QoL and is associated with lower rates of depression. With respect to HIV exposure, our study found no association with lower QoL scores. In contrast with our results, a 2004 U.S. study conducted by Oetzel et al. ${ }^{25}$ found a negative association between QoL, perceived social support and social undermining on HIV-seropositive individuals. Studies conducted by Li et al. ${ }^{26}$ and Johnson et al. ${ }^{27}$ found that social support mitigates the negative impact of depression on the QoL of people with HIV. Ashaba et al. ${ }^{28}$ have recently found that pregnancy is a stressful period for HIV-seropositive women. Anxiety, health-related fears and uncertainty about the infant's future are common in HIV-infected women and may compromise treatment engagement and reduce the QoL of both mother and child, resulting in significant anxiety in various domains. There was no difference between 
the association of depressive symptoms with QoL scores among HIV-seropositive and HIV-seronegative pregnant women, perhaps because pregnant women exposed to HIV performed prenatal care with a high-risk prenatal team that provided support and clarification regarding the stigma of HIV.

These findings should be interpreted in the light of some limitations. The sample size was not estimated for the aim of the current study. Thus, perhaps a larger sample size will be needed to detect a significant interaction between HIV exposure and depressive symptoms impacting QoL. However, an advantage of this study was the inclusion of HIV-seropositive pregnant women, a population little studied yet. In addition, validated instruments and techniques were used.
Depressive symptoms were significantly more prevalent in HIV-seropositive postpartum women, although it was not possible to correlate HIV infection with lower QoL scores. The presence of depressive symptoms was significantly associated with lower QoL in all domains, regardless of HIV serostatus. In conclusion, during pregnancy and puerperium, the health care team should be attentive to diagnosis and treatment of depressive symptoms, aiming to improve the QoL of these patients.

\section{Funding}

HCPA Research Incentive Fund (FIPE-HCPA).

\section{Conflicts of Interest}

The authors declare no conflicts of interest.

\section{REFERENCES}

1. World Health Organization (WHO). The World Health Organization Quality of Life assessment (WHOQOL): position paper from the World Health Organization. Soc Sci Med. 1995;41(10):1403-9. http://dx.doi. org/10.1016/0277-9536(95)00112-K. PMid:8560308.

2. Mourady D, Richa S, Karam R, Papazian T, Hajj Moussa F, El Osta $\mathrm{N}$, et al. Associations between quality of life, physical activity, worry, depression and insomnia: a cross-sectional designed study in healthy pregnant women. PLoS One. 2017;12(5):e0178181. http://dx.doi. org/10.1371/journal.pone.0178181. PMid:28542529.

3. Kapetanovic S, Dass-Brailsford P, Nora D, Talisman N. Mental health of HIV-seropositive women during pregnancy and postpartum period: a comprehensive literature review. AIDS Behav. 2014;18(6):1152-73. http:// dx.doi.org/10.1007/s10461-014-07289. PMid:24584458.

4. Collins PY, Holman AR, Freeman MC, Patel V. What is the relevance of mental health to HIVIAIDS care and treatment programs in developing countries? A systematic review. AIDS. 2006;20(12):157182. http://dx.doi.org/10.1097/01. aids.0000238402.70379.d4. PMid:16868437.

5. Tirado MC, Bortoletti FF, Nakamura MU, Souza E, Soárez PC, Castelo A Fo, et al. Quality of life of pregnant women infected with the human immunodeficiency virus (HIV) in the city of São Paulo. Rev Bras Ginecol Obstet. 2014;36(5):228-32. http://dx.doi.org/10.1590/S01007203201400050008 . PMid:25003475.

6. Peltzer K, Rodriguez VJ, Jones D. Prevalence of prenatal depression and associated factors among HIVpositive women in primary care in Mpumalanga province, South Africa. SAHARA J. 2016;13(1):60-7. http:// dx.doi.org/10.1080/17290376.2016.11 89847. PMid:27250738.

7. Calvetti P, Giovelli GRM, Gauer GJC, Moraes JFD. Psychosocial factors associated with adherence to treatment and quality of life in people living with HIVIAIDS in Brazil. $J$ Bras Psiquiatr. 2014;36(1):8-15. http://dx.doi.org/10.1590/00472085000000002.

8. Shrivastava SR, Shrivastava PS, Ramasamy J. Antenatal and postnatal depression: a public health perspective. J Neurosci Rural Pract. 2015;6(1):116-9. http://dx.doi. org/10.4103/0976-3147.143218. PMid:25552868.

9. Tani F, Castagna V. Maternal social support, quality of birth experience, and post-partum depression in primiparous women. J Matern Fetal Neonatal Med. 2017;30(6):689. PMid:27123699.
10. Lagadec N, Steinecker M, Kapassi A, Magnier AM, Chastang J, Robert $S$, et al. Factors influencing the quality of life of pregnant women: a systematic review. BMC Pregnancy Childbirth. 2018;18(1):455. http:// dx.doi.org/10.1186/s12884-018-20874. PMid:30470200.

11. Associação Brasileira de Empresas de Pesquisa (ABEP). Critério de Classificação Econômica-Brasil. São Paulo; 2015. [cited 2016 Oct 10]. Available from: http://www.abep.org/ criterioBrasil.aspx

12. Santos IS, Matijasevich A, Tavares BF, Barros AJ, Botelho IP, Lapolli $C$, et al. Validation of the Edinburgh Postnatal Depression Scale (EPDS) in a sample of mothers from the 2004 Pelotas Birth Cohort Study. Cad Saude Publica. 2007;23(11):257788. http://dx.doi.org/10.1590/ S0102-311X2007001100005. PMid:17952250.

13. Fleck MP, Louzada S, Xavier M, Chachamovich E, Vieira G, Santos $\mathrm{L}$, et al. Application of the Portuguese version of the abbreviated instrument of quality life WHOQOL-bref. Rev Saude Publica. 2000;34(2):17883. http://dx.doi.org/10.1590/ S0034-89102000000200012. PMid:10881154.

14. Koenig LJ, Espinoza L, Hodge K, Ruffo N. Young, seropositive, and pregnant: epidemiologic and psychosocial perspectives on pregnant adolescents with human 
immunodeficiency virus infection. Am J Obstet Gynecol. 2007;197(3 Suppl):S123-31. http://dx.doi. org/10.1016/j.ajog.2007.03.004. PMid:17825643.

15. Lima YA, Reis MN, Cardoso LP, Stefani MM. HIV-1 infection and pregnancy in young women in Brazil: socioeconomic and drug resistance profiles in a crosssectional study. BMJ Open. 2016;6(7):e010837. http://dx.doi. org/10.1136/bmjopen-2015-010837. PMid:27381205.

16. Brasil. Ministério da Saúde. Secretaria de Vigilância em Saúde. Departamento de DST, Aids e Hepatites Virais. Boletim epidemiológico HIV AIDS. Brasília; 2015. 100 p. [cited 2016 Oct 10]. Available from: www.aids.gov.br

17. Yaya S, Bishwajit G, Danhoundo G, Shah V, Ekholuenetale M. Trends and determinants of HIVIAIDS knowledge among women in Bangladesh. BMC Public Health. 2016;16(1):812. http:// dx.doi.org/10.1186/s12889-016-35120. PMid:27535231.

18. Pons-Duran C, González R, Quintó L, Munguambe K, Tallada J, Naniche $D$, et al. Association between HIV infection and socio-economic status: evidence from a semirural area of southern Mozambique. Trop Med Int Health. 2016;21(12):1513-21. http://dx.doi.org/10.1111/tmi.12789. PMid:27696629.

19. Arab K, Czuzoj-Shulman N, Spence A, Abenhaim HA. Obstetrical outcomes of patients with HIV in pregnancy, a population based cohort.
Obstet Gynecol. 2016;127(Suppl 1):10S. http://dx.doi.org/10.1097/01. AOG.0000483641.28007.ca.

20. Coelho NL, Cunha DB, Esteves AP, Lacerda EM, Theme MM Fa. Dietary patterns in pregnancy and birth weight. Rev Saude Publica. 2015;49(0):62. http://dx.doi.org/10.1590/ S0034-8910.2015049005403. PMid:26398873.

21. Donald KAM, Fernandez A, Claborn K, Kuo C, Koen N, Zar H, et al. The developmental effects of HIV and alcohol: a comparison of gestational outcomes among babies from South African communities with high prevalence of HIV and alcohol use. AIDS Res Ther. 2017;14(1):28. http:// dx.doi.org/10.1186/s12981-0170153-z. PMid:28482927.

22. Costa TP, Leal MC, Mota JC, Machado ES, Costa E, Vianna $\mathrm{P}$, et al. Comparison of pregnancy characteristics and outcomes between HIV-infected and HIV-noninfected women in Brazil. AIDS Care. 2013;25(6):686-90. http://dx.doi.or g/10.1080/09540121.2013.764382. PMid:23394727.

23. Sut HK, Asci O, Topac N. Sleep quality and health-related quality of life in pregnancy. J Perinat Neonatal Nurs. 2016;34(4):302-9. http://dx.doi. org/10.1097/JPN.0000000000000181. PMid:27223099.

24. Shrestha R, Copenhaver M, Bazazi AR, Huedo-Medina TB, Krishnan A, Altice FL. A moderated mediation model of HIV-related stigma, depression, and social support on health-related quality of life among incarcerated Malaysian men with HIV and opioid dependence. AIDS Behav. 2017;21(4):1059-69. http://dx.doi. org/10.1007/s10461-017-1693-x. PMid:28108877.

25. Oetzel J, Wilcox B, Archiopoli A, Avila M, Hell C, Hill R, et al. Social support and social undermining as explanatory factors for health-related quality of life in people living with HIVIAIDS. $J$ Health Commun. 2014;19(6):660-75. http://dx.doi.org/10.1080/10810730.20 13.837555. PMid:24479678.

26. Li X, Li L, Wang H, Fennie KP, Chen J, Williams AB. Mediation analysis of health-related quality of life among people living with HIV infection in China. Nurs Health Sci. 2015;17(2):250-6. http:// dx.doi.org/10.1111/nhs.12181. PMid:25496799.

27. Johnson JG, Alloy LB, Panzarella C, Metalsky GI, Rabkin JG, Williams JB, et al. Hopelessness as a mediator of the association between social support and depressive symptoms: findings of a study of men with HIV. J Consult Clin Psychol. 2001;69(6):1056-60. http://dx.doi. org/10.1037/0022-006X.69.6.1056. PMid:11777109.

28. Ashaba S, Kaida A, Coleman JN, Burns BF, Dunkley E, O'Neil K, et al. Psychosocial challenges facing women living with HIV during the perinatal period in rural Uganda. PLoS One. 2017;12(5):e0176256. http://dx.doi.org/10.1371/journal. pone.0176256. PMid:28459866.

Received: Feb 14, 2019 Accepted: May 6, 2019 